\title{
A rare case of gastric wall abscess arising after endoscopic ultrasound-guided fine-needle aspiration of solid pancreatic mass
}
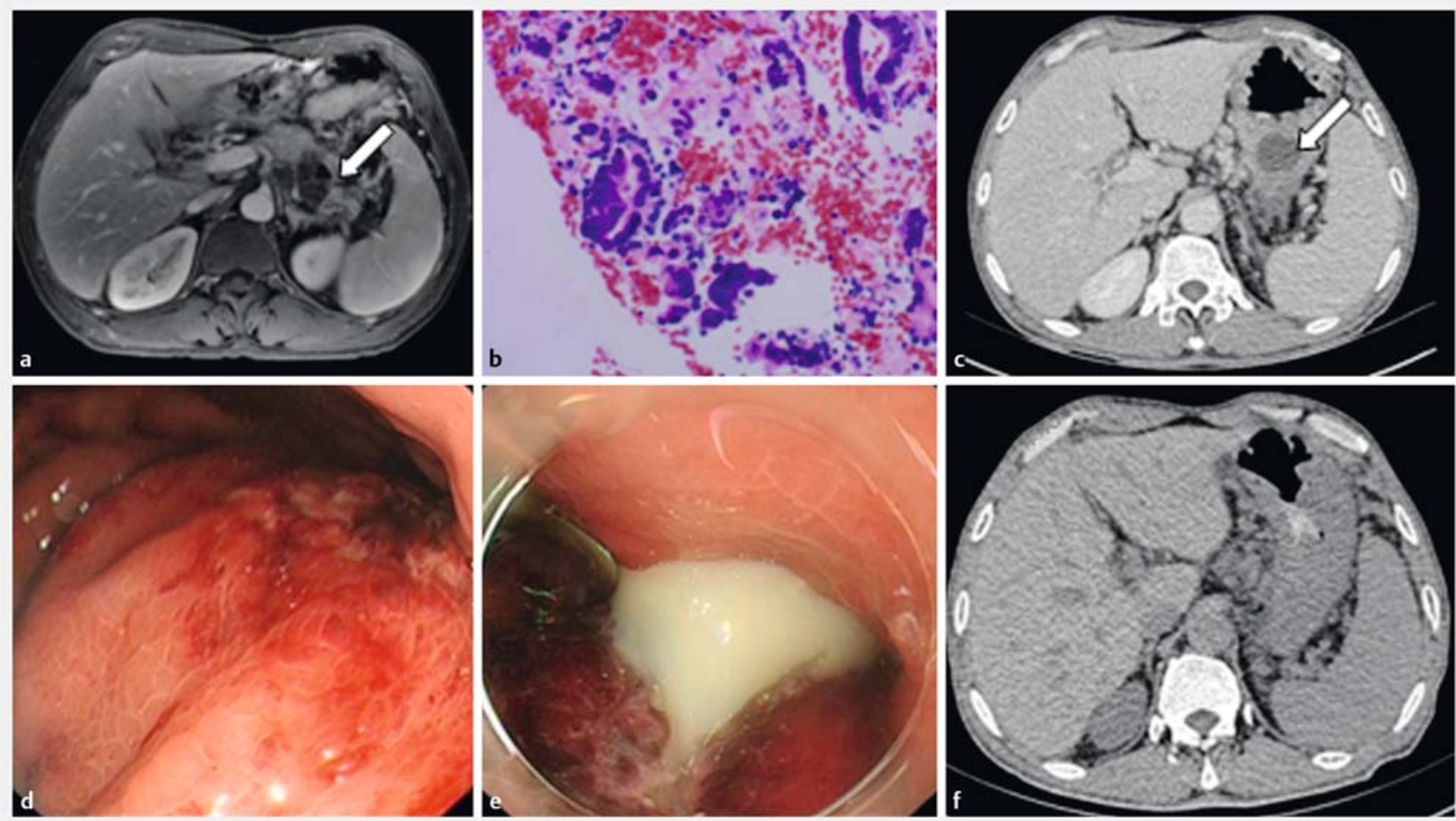

- Fig. 1 Abscess of the stomach wall associated with endoscopic ultrasound-guided fine-needle aspiration (EUS-FNA) of a solid pancreatic mass. a Magnetic resonance imaging showed a mass in the pancreatic body (arrow). b The pathological diagnosis was severe dysplastic glands and cells; adenocarcinoma was suspected. c Computed tomography (CT) scan showed a hypoattenuating lesion in the posterior stomach wall (arrow), which occurred 7 days after EUS-FNA. $\mathbf{d}$ Gastroscopy showed a submucosal mass in the posterior wall of the stomach body. e White pus flowed out after endoscopic incision with a hook knife. $\mathrm{A}$ A second CT scan on the 10th day after endoscopic therapy showed that the abscess had disappeared.

A 55-year-old man was admitted to our hospital because of a 7-month history of upper abdominal pain. The magnetic resonance imaging (MRI) scan showed a solid mass occupying the body and tail of the pancreas ( $\mathbf{F i g . 1} \mathbf{a}$ ). To make a more definitive diagnosis, endoscopic ultrasound-guided fine-needle aspiration (EUS-FNA) was carried out with a 22-gauge needle (EchoTip Ultra HD; Wilson-Cook Medical Inc., Winston Salem, North Carolina, USA). In total, five passes were completed using a fanning technique. Pathological examination of the collected tissue revealed severe atypical epithelial cells, and adenocarcinoma was suspected (> Fig.1 b). Combined with
MRI images, we clinically diagnosed pancreatic adenocarcinoma.

One week later, the patient developed increasing upper abdominal pain with high fever. Laboratory examination showed a white blood cell count of 6020 cells $/ \mu \mathrm{L}$ and an elevated C-reactive protein (CRP) level of $182.7 \mathrm{mg} / \mathrm{dL}$. Computed tomography $(C T)$ scan revealed a hypoattenuating mass in the posterior stomach wall (•Fig.1c). The patient was diagnosed with a gastric wall abscess that developed after EUS-FNA. Antibiotic therapy with meropenem was started, but after 3 days the response was poor. Therefore, endoscopic drainage was initiated.
A hook knife (KD-620QR HookKnife; Olympus Corp., Tokyo, Japan) was used to make an incision in the mucosa ( $\triangleright$ Fig.1d,e, $\triangleright$ Video 1). Two days after endoscopic drainage, the abdominal pain and fever disappeared, and the CRP level decreased to normal ranges. A second CT scan on the 10th day after endoscopic therapy showed that the abscess

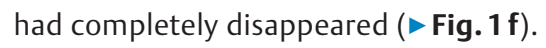
The main postoperative complications of EUS-FNA include bleeding, perforation, infection, and acute pancreatitis, with a total morbidity of $1.2 \%$ [1]. Infectious complications associated with EUS-FNA of solid lesions are infrequent, with an incidence of $0-0.6 \%[2,3]$. Abscess of the 


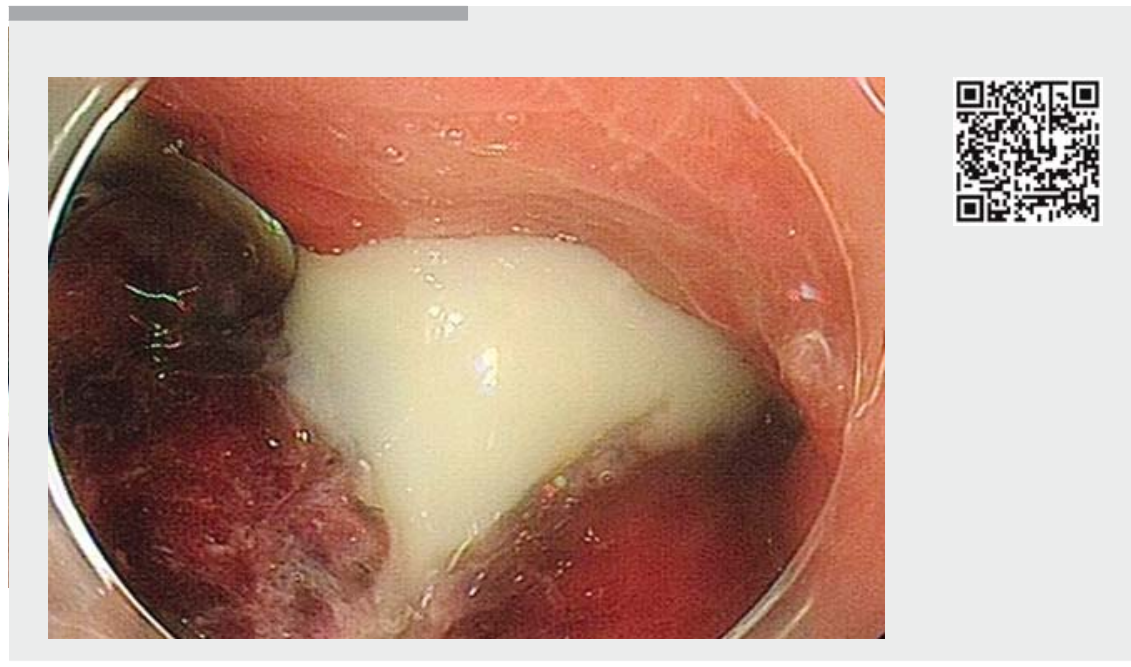

$\checkmark$ Video 1 Endoscopic treatment of a gastric wall abscess. Sufficient drainage of pus was made by exposing the abscess cavity with a hook knife and pressing a transparent cap against the gastric wall.

stomach wall arising from EUS-FNA is extremely rare. From our experience, endoscopic incision and drainage seems to be an efficient treatment for such complication.

Endoscopy_UCTN_Code_CPL_1AL_2AD

\section{Competing interests}

None Zhou $^{2}$, Guo-chun Lou ${ }^{1}$

1 Department of Gastroenterology, Zhejiang Provincial People's Hospital, People's Hospital of Hangzhou Medical College, Hangzhou, China Institute for Nutritional Sciences, Shanghai Institutes for Biological Sciences, Graduate School of the Chinese Academy of Sciences,
[1] Polkowski M, Larghi A, Weynand B et al. Learning, techniques, and complications of endoscopic ultrasound (EUS)-guided sampling in gastroenterology: European Society of Gastrointestinal Endoscopy (ESGE) Technical Guideline. Endoscopy 2011; 44: 190 206

[2] Eloubeidi MA, Tamhane A, Varadarajulu S et al. Frequency of major complications after EUS-guided FNA of solid pancreatic masses: a prospective evaluation. Gastrointest Endosc 2006; 63: 622-629

[3] Levy M], Norton ID, Clain JE et al. Prospective study of bacteremia and complications with EUS FNA of rectal and perirectal lesions. Clin Gastroenterol Hepatol 2007; 5: 684-689

\section{Bibliography}

DOI https://doi.org/10.1055/s-0043-123818

Published online: 9.4.2018

Endoscopy 2018; 50: E142-E143

(c) Georg Thieme Verlag KG

Stuttgart · New York

ISSN 0013-726X

Weiquan Q. Wu ${ }^{1}$, Jing Du ${ }^{1}$, Jian-min Yang ${ }^{1}$, Bin

2 Key Laboratory of Nutrition and Metabolism, Chinese Academy of Sciences, Shanghai, China

\section{Corresponding author}

\section{Guo-chun Lou, MD}

Department of Gastroenterology, Zhejiang Provincial People's Hospital, People's

Hospital of Hangzhou Medical College,

Hangzhou 310014, China

Fax: +86-571-85131448

louguochun@hmc.edu.cn

\section{ENDOSCOPY E-VIDEOS}

https://eref.thieme.de/e-videos

回回 Endoscopy E-Videos is a free access online section, reporting 自: on interesting cases and new techniques in gastroenterological endoscopy. All papers include a high quality video and all contributions are freely accessible online.

This section has its own submission website at https://mc.manuscriptcentral.com/e-videos 